\title{
Mental health of homeless children and their families
}

\author{
Panos Vostanis
}

Homeless families are defined as all adults with dependent children who are statutorily accepted by local authorities (housing departments) in the UK, and are usually accommodated for a brief period in voluntary agency, local authority or housing association hostels. This period varies from a few days to several months, although the target for rehousing is usually around 4 to 6 weeks. Some housing departments, particularly in London, also use bed and breakfast accommodation.

This definition is obviously fairly broad and does not include those children and their carers who have lost their homes and live with friends or relatives, on the streets, in squats or as travellers. For this reason, official statistics are not often accurate, although it is estimated that about 140000 families in the UK fulfil these criteria each year (Vostanis \& Cumella, 1999). Many of these families become homeless again within 1 year of rehousing. The average family comprises a single mother and at least two children (usually under 11 years), although there are a number of adolescents and fathers living in homeless centres.

On the whole, reasons for family homelessness are different from those for single homeless adults. The majority of families become homeless because of domestic violence and, to a lesser extent, harassment from neighbours. In our epidemiological studies (Vostanis et al, 1997), the corresponding figures were $50 \%$ and $25 \%$. These very much depend on the type of accommodation, as most local authorities or voluntary organisations (for example, Women's Aid or Crisis Response) have hostels exclusively or predominantly for victims of domestic violence. The proportion of families who are refugees has fluctuated since the late 1990s. Initially, they were confined to the London area, but in the past few years their numbers have been rising in most parts of the UK. There is, however, an increasing tendency for refugees not to go through the above homelessness route. Similar trends in homelessness have been evident in other Western societies, mainly in North America (Weinreb \& Rossi, 1995; Bassuk et al, 1996; Better Homes Fund, 1999).

\section{Characteristics and needs}

Homeless children and families are a heterogeneous population, with multiple and interrelated needs. This is a crucial observation for the development of services. The episode of homelessness is rarely a one-off event. Most families have histories of previous chronic adversities that constitute risk factors for both children and parents (Bassuk et al, 1997). Such events include family conflict, violence and breakdown; limited or absent networks for family and social support; recurring moves; poverty; and unemployment. Mothers are more likely to have suffered abuse in their own childhood and adult life and children have increased rates of placement on the at-risk child protection register, because of neglect, physical and/or sexual abuse.

Studies have looked at a range of health needs among homeless children and their parents. Not surprisingly, a number of problems appear to cluster in this population. In particular, the children are more likely to have a history of low birthweight,

Panos Vostanis is Professor of Child and Adolescent Psychiatry at the University of Leicester (Greenwood Institute of Child Health, Westcotes House, Westcotes Drive, Leicester LE3 0QU, UK. Tel: 0116225 2880; fax: 0116225 2881; e-mail: pv11@le.ac.uk). In his National Health Service (NHS) capacity, he provides a mental health service for children looked after by local authorities, youth offenders and homeless families. The research projects on homeless children have been supported by the Nuffield Foundation (1996-1998), West Midlands NHS Executive Research and Development (1998-2000) and, currently, the PPP Healthcare Medical Trust. 
anaemia, dental decay and delayed immunisations, to be of lower stature and have a greater degree of nutritional stress. They are also more likely to suffer accidents, injuries and burns. Some studies have found that child health problems increase with the duration of homelessness, although this finding is not consistent. A substantial proportion of homeless children have delayed development compared with the general population of children of a similar chronological age. This includes both specific developmental delays, such as in receptive and expressive language and visual, motor and reading skills, as well as general skills and educational status (Page et al, 1993; Webb et al, 2001).

\section{Mental health problems and disorders}

The social profile of homeless children includes many well-established risk factors for the development and maintenance of psychopathology. These are not specific to child or adult psychiatric disorders, as research has found high prevalence rates for a number of emotional and behavioural problems and disorders (Amery et al, 1995). In children of pre-school and primary school age, behavioural problems include sleep disturbance, feeding problems, aggression and hyperactivity. These are often comorbid with emotional or developmental disorders. Anxiety and posttraumatic stress disorder (PTSD) are often precipitated by life events such as witnessing domestic violence. About one-third of children admitted to hostels in Birmingham were reported to have mental health problems which required clinical assessment and treatment (Vostanis et al, 1997). Histories of abuse and the presence of mental illness in mothers were the strongest predictors of child psychopathology. In the absence of any intervention, child mental health problems remained 1 year later (Vostanis et al, 1998). In a subsequent cohort, mental health problems among both children and their mothers were strongly associated with poor family and social support networks (Vostanis et al, 2001).

Homeless adolescents and street youth are likely to present with depression and attempted suicide, alcohol and drug misuse, and vulnerability to sexually transmitted diseases, including acquired immune deficiency syndrome (AIDS). Two major studies of this group in London (Craig et al, 1996) and Edinburgh (Wrate \& Blair, 1999) found significant histories of residential care, family breakdown, poor educational attainment and instability of accommodation. These were associated with sexual risk behaviours, substance misuse and comorbid psychiatric disorders, particularly depression. A high proportion of homeless mothers also have similar psychiatric disorders, again primarily depression and substance misuse. Prevalence rates of $45-50 \%$ have been reported (Connelly \& Crown, 1994; Zima et al, 1996; Vostanis et al, 1997). These are similar to rates found among single homeless women (Adams et al, 1996).

\section{Access to services}

There are several reasons why homeless children and their families cannot access mainstream health and social care services, despite their high level of need. The main one is their mobility between different health and local authority sectors. As most families will have changed address frequently or urgently, they are less likely than the rest of the population to be registered with a general practitioner (GP) or, in the best of situations, to be registered as temporary patients with a GP covering the hostel residents. This reduces their access to primary and secondary medical care as well as to immunisations and other preventive health procedures (Brooks et al, 1998). Homeless families therefore, tend to rely on accident and emergency departments for medical treatment and to have high rates of hospital admission (Lissauer et al, 1993).

The same applies to social services (access teams, family teams and family support units) and other community agencies. Homeless children are also more likely to be out of school, to avoid being traced by a violent ex-partner or because of the distance from the hostel (particularly in large cities). Parents may wait until they know where they are to be rehoused before registering the children with a new nursery or school. Nurseries and primary schools in the proximity of hostels usually have a high pupil turnover, with resulting high costs, and there are often limited vacancies for short periods (Power et al, 1995). These problems are compounded for refugee children. The outcome is that children miss out on their only source of social stability, i.e. their peers, their routines and a sense of achievement, which are important protective factors.

Apart from the organisational problems in accessing services, considering the frequency of child protection incidents and registrations, children may also be at increased risk because of a lack of continuity and information transfer as they often move between different parts of the country and local social services departments may not be aware of their previous history or be informed of it sufficiently well in advance. 
Box 1 The three tiers of intervention in child mental health

Tier 1 Primary care, predominantly for children with behavioural and low-severity emotional problems

Tier 2 The interface between primary care and professionals from specialist multi-disciplinary teams for psychiatric and developmental disorders

Tier 3 Specialist multi-disciplinary teams for psychiatric and developmental disorders

These family and service characteristics inevitably have an impact on any potential contact with mental health services. They are less obvious for adults with mental illness, who may be known to local services. However, psychiatric cover of a hostel can be a contentious issue, as residents can be classified as having no fixed abode. The local service may argue that this population substantially increases the number of referrals and therefore requires extra resources. Areas with such additional resources usually target them at the single adult homeless population, where it is more likely that there will be individuals presenting with severe mental illness. It is more difficult to provide cover for parents with depressive or anxiety disorders, self-harm and substance misuse. In our research (Cumella et al, 1998), homeless mothers had a $49 \%$ prevalence rate of psychopathology and an $11 \%$ rate of contact with mental health services in the previous year, compared with the corresponding rates for children of 30\% (need) and 3\% (contact with child and adolescent mental health services (CAMHS)).

Child and adolescent mental health services are undergoing an unprecedented change, seeking to improve their accessibility and response to the general population by distinguishing between different levels of intervention (Box 1). Adopting such a service model is even more important for homeless children who cannot at present access services structured around stability and waiting lists for assessment and treatment. Ways of addressing these problems are discussed below.

\section{Setting up a new service}

The nature and complexity of child and family mental health and related needs indicate that plans for the development of a new service should involve key agencies from the outset. The service should be incorporated into inter-agency policy and commissioning documents, have clear objectives, particular mechanisms for reviewing its specifications, and a built-in evaluation process. Because of their characteristics, homeless children and other socially excluded young populations such youth offenders and children cared for by local authorities should be included in all children's strategies as a group in need (in contrast with a group requiring 'specialist' service provision). The service should also include policies such as health improvement plans, social services Quality Protects, and local educational authority standards. It is also important that all health authorities (or primary care groups) and housing departments have a local strategy for homeless people (children, families, single youths and adults). Such a framework will ensure that this population no longer slips through the wider service net nor is overlooked with regard to new resources. Similarly, it will ensure that existing mainstream mental health services do not become antagonistic because of the burden of a heavy additional caseload without extra support. Child and adult mental health services need to have joint arrangements for a cost-effective service provision to children and their parents.

There are many central and local government initiatives that could be relevant and provide new resources, in partnership with the local CAMHS rather than through exclusive CAMHS funding. These include Health Action Zones or grants for urban regeneration. Such cooperation will obviously depend on the preferred direction of the service. Policy-makers, senior managers and practitioners from all partner agencies need to meet at regular intervals through a multi-agency steering group to monitor and facilitate the contribution of each agency.

Two service models are described below, one adopting a mental health outreach approach and the other a family support service with broader operational criteria.

\section{Mental health service objectives}

A new service should set clear and achievable objectives. It is essential to identify children with mental health problems and disorders as being within a high-risk group. Compared with a stable family population, homeless children have no service filters such as GPs, teachers and paediatricians. It is the mental health service, or any other agency providing a direct input to the hostels, that 
will have to develop effective screening and referral mechanisms for families who are admitted in crisis, often without any previous records. This may provide a unique opportunity to become aware of child protection concerns, special educational needs and the involvement of social services or education agencies, and of mental health problems and disorders that would respond to treatment.

Because developmental, physical health, educational and social care needs coexist, this indicates that liaison and consultation between agencies are important to serve those undergoing a period of homelessness.

This cooperation is also a pre-requisite for establishing appropriate agency involvement in the family's next area of residence. This may involve domestic violence or adult mental health services, the education welfare officer, health visitor, parenting groups, social services access team and the local area CAMHS.

Brief interventions can be provided in appropriate cases, preferably starting at the hostel and continuing after rehousing. Family and individual therapy modalities need to be applied for different client needs, rather than relying on family stability. This is an important factor in engaging homeless families. Parent-training programmes in both the community and hospital-based CAMHS have been found to be effective for treatment of behavioural problems in young children (Harrington et al, 2000). Brief psychotherapy and cognitive-behavioural therapy are also effective for children and adults with PTSD (American Academy of Child and Adolescent Psychiatry, 1998). These are fairly common among victims of violence (McCloskey \& Walker, 2000). Training, at the appropriate level, of front-line (Tier 1) and hostel staff involved with these families is another important objective of a mental health service. This will enable consistent management of, for example, child behaviour problems in the hostel and at school, and will hopefully generate change when the family is in its next stable placement.

\section{Outreach child mental health service model}

A designated community child psychiatric nurse $(\mathrm{CPN})$ (or clinical nurse specialist) provides regular outreach sessions at identified centres for homeless families in Birmingham (Tischler et al, 2000). However, a flexible response is available, if necessary. The CPN is based at the local CAMHS and has some involvement in the generic (catchment area) service. To avoid screening every admission, referral criteria have been established, either in relation to mental health concerns in parents and

\section{Box 2 Objectives of outreach mental health services for homeless children}

Identification of child mental health problems of clinical significance

Mental health assessment

Treatment:

- parent training and behaviour management

- anxiety management

- brief psychotherapy

- cognitive-behavioural therapy

- family work and therapy

Liaison with other agencies

Consultation with other agencies

Referral to local mental health services after rehousing

Training for hostel and multi-agency front-line (Tier 1) staff

children (including learning disability) or through identification of high-risk families (victims of domestic violence and established or suspected child protection issues).

A weekly inter-agency meeting is held at each hostel, when all families are discussed. Direct work with children and families is bounded by constraints resulting from the brief length of stay and the complexity of psychosocial problems. Despite the limited period of involvement, direct work and treatment can be effective. Parents and staff are given time-limited behavioural therapy or advice on how to deal with the children's aggressive behaviour, bedwetting or sleep problems. Children who have experienced major trauma are offered brief supportive psychotherapy during this family transition (Box 2).

There are many similiarities between this model and established outreach adult mental health teams for homeless people (Commander et al, 1997). The model is strengthened by its links with the local CAMHS and the level of experience and skills of the post-holder. However, the overwhelming demand for assistance with problems outside the mental health area has caused difficulties. These include help with housing applications and benefits, nursery and school placements, initiation of special needs educational assessments and, particularly, child protection matters. The service would benefit from an additional post with a social work capacity to undertake these duties.

Homeless children receiving such a service were found to have significantly fewer behavioural problems at 6-month follow-up, i.e. after rehousing, compared with matched homeless children from 
hostels without access to the service (Tischler et al, 2002). Qualitative methods suggested that families and hostel staff were positive about the outreach service. It is interesting to note that positive experiences of the service often included a combination of practical help with psychotherapeutic work. As when working with other groups of socially deprived or excluded people, mental health staff may need to provide a more tangible support in parallel with the application of more traditional psychotherapies. This contrasts with specialist services, where it is easier to use an abstract framework from the onset of treatment.

\section{Family support service model}

A Tier 1 service with a family support team (four family support assistants) has been developed in Leicester. This is designed to detect a range of problems at the time of crisis; manage a degree of mental health problems (behavioural and emotional); provide parenting- training; support and train housing (hostel) staff; coordinate the work of different agencies; and provide some continuity after rehousing by ensuring intake by appropriate local services. The family workers are based at the main hostel for homeless children and families. Other, predominantly voluntary, services have established alternative posts, such as advocates and key workers. Whatever the title of the post, it is essential that the post-holder has some experience and ongoing training in mental health and child protection, so that he or she can hold a substantial case-load, rather than merely mediate between already limited services.

The family support workers in Leicester have direct access to the local child and adult mental health services, whose staff provide weekly outreach clinics. Their role is to work with the family support workers and other agencies, assess selected children and families, and provide treatment for more severe problems or disorders such as depression, self-harm and PTSD. A weekly interagency liaison meeting at the main hostel is attended by a health visitor, representatives of the local domestic violence service and Sure Start, and a CPN for single adult homeless people. There are also close, regular links with education welfare and social services. The aim is to effectively utilise specialist skills by discussing family situations from all perspectives at the liaison meeting. A bimonthly steering group, led by the housing department, involves senior managers representing these agencies, as well as the education and social services departments and the voluntary sector, and they oversee and coordinate the service.

\section{Case vignettes}

\section{Case 1}

$\mathrm{L}$ is a 15-year-old girl who moved to the homeless centre with her father, following violence from the neighbours. The family support worker was concerned that $\mathrm{L}$ might have depression and asked the visiting child psychiatrist to see her. Two months before the family had become homeless, her elder sister (17 years old) had committed suicide by hanging herself. The sister had lived with her boyfriend and was in contact with her family.

The two girls had been brought up by their father as the mother had left the family when L was 11 months old. The family had moved around the UK and had been homeless. The father had chronic alcohol dependence and was frequently admitted to hospital for detoxification, during which time, L took responsibility of all the household tasks. She had been coping well at school, which she continued to attend while at the hostel.

On assessment, L presented with a grief reaction (tearful, hearing her sister's voice and seeing her image) and with several depressive features, mainly depressed mood, irritability, sleep disturbance and loss of appetite. There was also some indication that she could be developing an eating disorder. While at the hostel, she was followed up by both the family support worker and the child psychiatrist and, after rehousing, was referred to the local CAMHS. Her teachers and GP were alerted to the high risk of deterioration or relapse. The father was re-referred to the drug and alcohol service, from which he had previously lapsed.

\section{Case 2}

$\mathrm{P}$ is a 29-year-old single mother with two sons, A (aged 6) and R (aged 8). The family had become homeless after recurrent domestic violence from $P^{\prime}$ s partner (who was not the children's biological father). So far, she had declined to prosecute him or seek help as she was very frightened. The children had witnessed the violence and had become very anxious and insecure and would not let their mother out of their sight. The partner managed to keep contact with $\mathrm{P}$, even during her stay at the hostel. On several occasions, the staff saw bruises on her arms and face, but she would give no further information.

Both children had learning difficulties, particularly R, who had been given a statement of special educational needs. The mother was very concerned about A's behaviour. He was aggressive and overactive and had already been suspended from school on a number of occasions. She had threatened to place him into care. P felt depressed, suicidal and unable to cope, believing that it was all her fault.

As the hostel placement was not thought to be sufficiently safe, the family was transferred to a women's aid refuge (for victims of domestic violence). The family support worker started a brief programme of parent training with the family while they were at the centre and the mother was seen by the CPN and a domestic violence officer. Social services were involved because 
of the direct and indirect risks to the children. The family support worker also worked closely with those at the boys' school. Following rehousing, the social worker, the domestic violence officer and the CPN remained closely involved. The parenting programme continued at the local family centre, which also organised afterschool and holiday activities for the children.

Both of the above case studies are fictitious.

\section{Conclusions}

The principles of services for homeless children and their families apply to other socially excluded groups. Their multiple needs require a coordinated approach between child and adult mental health services and with other agencies. However, such a service for children and families should be based within CAMHS in order to provide continuity of treatment after the episode of homelessness. Interventions by CAMHS need to take into consideration the mobility and psychosocial characteristics of these families, i.e. apply theoretical models to brief treatment for specific psychiatric disorders. The preferred model is of a designated service that aims to use mainstream agencies, rather than 'specialist' isolated posts or teams. This could include one or more posts, or sessional input from CAMHS professionals. In order for child mental health staff to provide focused clinical interventions, it is desirable that a family support worker, or similar post, acts as a first filter for a broad assessment of social, educational and health needs. This individual should also give behavioural therapy and parent training. Ideally, this post will provide continuity of care for at least a few months into the family's return to the community. This is a gap in current service provision.

Another cause for concern is the lack of local and national coordination in developing services for homeless families. A national mechanism for advising, monitoring and coordinating local forums, and a national database on clients and services are a realistic goal for central and local government. It is recognised that cultural and local organisational characteristics will need to be taken into account and that a range of service models will evolve within a national framework. For this reason, ongoing research evaluation should be an integral component of all new services.

\section{References}

Adams, C. E., Pantelis, C. J., Duke, P., et al (1996) Psychopathology, social and cognitive functioning in a hostel for homeless women. British Journal of Psychiatry, $168,82-86$.
American Academy of Child and Adolescent Psychiatry (1998) Practice parameters for the assessment and treatment of children and adolescents with posttraumatic stress disorder. Journal of the American Academy of Child and Adolescent Psychiatry, 37 (suppl. 10), 4S-26S.

Amery, J., Tomkins, A. \& Victor, C. (1995) The prevalence of behavioural problems amongst homeless primary school children in an outer London borough. Public Health, 109, 421-424.

Bassuk, E., Weinreb, L., Buckner, J., et al (1996) The characteristics and needs of sheltered homeless and low-income housed mothers. Journal of the American Medical Association, 276, 640-646.

- Buckner, J., Weinreb, L., et al (1997) Homelessness in female-headed families: childhood and adult risk and protective factors. American Journal of Public Health, 87, 241-248.

Better Homes Fund (1999) America's Homeless Children: New Outcasts. Newton, MA: Better Homes Fund Publications.

Brooks, R., Ferguson, T. \& Webb, E. (1998) Health services to children resident in domestic violence shelters. Ambulatory Child Health, 4, 369-374.

Commander, M., Odell, S. \& Sashidharan, S. (1997) Birmingham community mental health for the homeless. Psychiatric Bulletin, 21, 74-76.

Connelly, J. \& Crown, J. (eds) (1994) Homelessness and Ill Health: Report of a Working Party of the Royal College of Physicians. London: Royal College of Physicians of London.

Craig, T., Hodson, S., Woodward, S., et al (1996) Off to a Bad Start: a Longitudinal Study of Homeless Young People in London. London: The Mental Health Foundation.

Cumella, S., Grattan, E. \& Vostanis, P. (1998) The mental health of children in homeless families and their contact with health, education and social services. Health and Social Care in the Community, 6, 331-342.

Harrington, R., Peters, S., Green, J., et al (2000) Randomised comparison of the effectiveness and costs of community and hospital based mental health services for children with behavioural disorders. BMJ, 321, 1047-1050.

Lissauer, T., Richman, S., Tempia, M., et al (1993) Influence of homelessness on acute admissions to hospital. Archives of Disease in Childhood, 69, 423-429.

McCloskey, L. A. \& Walker, M. (2000) Posttraumatic stress in children exposed to family violence and single-event trauma. Journal of the American Academy of Child and Adolescent Psychiatry, 39, 108-115.

Page, A., Ainsworth, A. \& Pett, M. (1993) Homeless families and their children's health problems: a Utah urban experience. Western Journal of Medicine, 158, 30-35.

Power, S., Whitty, G. \& Youdell, D. (1995) No Place to Learn: Homelessness and Education. London: Shelter.

Tischler, V., Cumella, S., Bellerby, T., et al (2000) Service innovations: a mental health service for homeless children and families. Psychiatric Bulletin, 24, 339-341.

- Vostanis, P., Bellerby, T., et al (2002) Evaluation of a mental health outreach service for homeless families. Archives of Disease in Childhood, 86, 158-163.

Vostanis, P. \& Cumella, S. (eds) (1999) Homeless Children: Problems and Needs. London: Jessica Kingsley.

- Grattan, E., Cumella, S., et al (1997) Psychosocial functioning of homeless children. Journal of the American Academy of Child and Adolescent Psychiatry, 36, 881-889.

- - _ \& - (1998) Mental health problems of homeless children and families: longitudinal study. BMJ, 316, 899-902.

- Tischler, V., Cumella, S., et al (2001) Mental health problems and social supports among homeless mothers and children victims of domestic and community violence. International Journal of Social Psychiatry, 47, 30-40.

Webb, E., Shankleman, J., Evans, M., et al (2001) The health of children in refuges for women victims of domestic violence. $B M J, 323,210-213$.

Weinreb, L. \& Rossi, P. H. (1995) The American homeless family shelter 'system'. Social Service Review, 69, 86-107.

Wrate, R. \& Blair, C. (1999) Homeless adolescents. In Homeless Children: Problems and Needs (eds P. Vostanis \& S. Cumella), pp. 83-96. London: Jessica Kingsley. 
Zima, B., Wells, K., Benjamin, B., et al (1996) Mental health problems among homeless mothers: relationship to service use and child mental health problems. Archives of General Psychiatry, 53, 332-338.

\section{Multiple choice questions}

1. Homeless families have high levels of:
a children and adults with learning disability
$\mathrm{b}$ children with special educational needs
c child abuse and neglect
d mothers with psychosis
e victims of domestic violence.

2. The following treatment modalities can be used with homeless children and their parents:
a parent training
b cognitive-analytic therapy
c brief psychodynamic therapy
d cognitive-behavioural therapy
e long-term psychotherapy.

3. Common agencies and procedures for the management of domestic violence include:
a the police domestic violence unit
b Women's Aid
c referring children to CAMHS
d involving social services
e psychotherapy.

4. Core features of a child mental health service for homeless children include:
a a sectorised approach
b joint work with the adult mental health service
c training for front-line staff
d assessment of child protection cases
e assessment of special educational needs.

5. Resources for a new service should:
a aim at appointing a team
b come from core CAMHS funding
c include designated time of existing CAMHS staff
d consider joint funding with local authorities e be managed by CAMHS.

\begin{tabular}{|c|c|c|c|c|c|}
\hline \multicolumn{6}{|c|}{ MCQ answers } \\
\hline 1 & 2 & 3 & 4 & & 5 \\
\hline a $\mathbf{F}$ & a $\mathrm{T}$ & a 7 & & F & a $F$ \\
\hline b $\mathrm{T}$ & b F & b & b & $\mathbf{T}$ & b F \\
\hline$T$ & c $T$ & c $\mathrm{I}$ & & $T$ & c $T$ \\
\hline $\mathbf{F}$ & d $T$ & d 7 & d & F & d $T$ \\
\hline $\mathbf{T}$ & e $F$ & e $\mathbf{I}$ & & $\mathbf{F}$ & \\
\hline
\end{tabular}

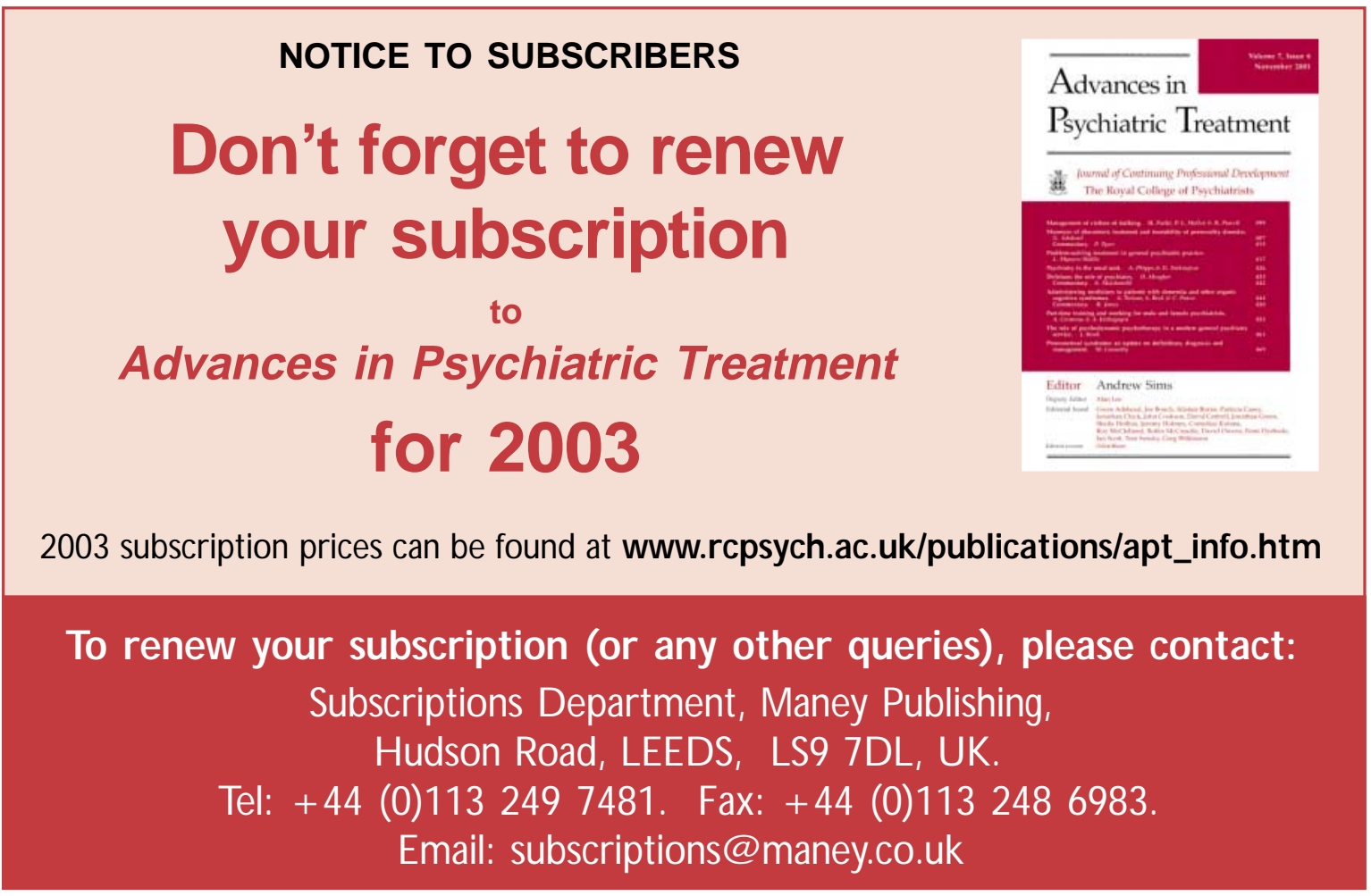

